\title{
FORMAÇÃO DE PROFESSORES EM TEMPOS DE INFORMÁTICA
}

\section{Uso das novas tecnologias no processo de ensino realça o papel do professor como agente de cultura}

Educar é sempre um desafio, pois trata de uma relação complexa e delicada entre pessoas. Quando a educação é escolar, acresce o fato de que a escola está sempre atrasada em relação aos avanços da ciência, pois ensina-se o que já está aceito e cristalizado. Está atrasada quanto ao futuro, pois não dá para prever as mudanças na formação social e no processo econômico/cultural a que os alunos estão sujeitos. Toda educação, no entanto, insere-se na perspectiva de um futuro. É imprescindível para a consecução do projeto de sociedade vigente, ainda que não totalmente explícito.

É preciso considerar que a escola contém espaços criativos, até porque nela há

\section{AS AUTORAS}

Célia Pezzolo de Carvalho

Professora Doutora do Departamento de Psicologia e Educação e do Laboratório de Ensino de Ciências da Faculdade de Filosofia, Ciências e Letras de Ribeirão Preto da USP.

Marisa Ramos Barbieri

Professora Doutora do Departamento de Psicologia e Educação e do Laboratório de Ensino de Ciências da Faculdade de Filosofia, Ciências e Letras de Ribeirão Preto da USP. agrupamentos de pessoas, as quais alimentam (arejam) os programas ditos oficiais. Há o currículo oculto, muito citado por teóricos da Educação, cuja relação com o previsto (oficial) é dificilmente mensurada (avaliada), embora percebida (sentida). O professor reconhece e estimula esse espaço extraclasse através de atividades (até com certa regularidade) do tipo olimpíadas, feiras, exposições, excursões, entre outros. Mas, até que ponto estas atividades e seus resultados são de fato incorporados aos programas para o seu devido reconhecimento ${ }^{1}$.

Há um outro espaço criativo, científico no qual o computador tem papel importante ao acelerar a organização, conferir os dados e analisá-los. Mas é preciso que os resultados, os produtos sejam avaliados dentro da trajetória, que é educacional, pois forma pessoas. É necessário que se considerem os professores como interlocutores natos entre o conhecimento e os alunos para que haja aprendizagem a qual é um processo humano permeado por relações pessoais ainda que na aparência comandado pela técnica.

O mundo é tanto tribal quanto universal - há uma comunicação generalizada, com multiplicação dos valores locais. A presença marcante dos meios eletrônicos de comunicação permite e até força uma convi-

1. Sobre o tema ver: TOURINHO. Irene. Promoção cultural e ensino: alguns desafios. Comunicação \& Educação. São Paulo: CCA-ECA-USP/Moderna, n.4, set./dez. 1995. p.35-40. 
vência entre culturas diferentes, invade os lares com doses maciças de informações rápidas e quase sempre sem ligação umas com as outras. Há um novo lugar, que assume o papel de lugar público, que é a tela da televisão e/ou o espaço virtual das redes de computadores. Potencialmente há um aumento de possibilidades de comunicação entre as pessoas, porém coexistem valores modernos com antigos; a TV tanto reina em um apartamento de classe alta como em um barraco de favela. As informações veiculadas pelo Jornal Nacional, a trama das novelas, o apelo ao consumo nas propagandas são os mesmos. O local da informação é um só, a tela. Mas, os formatos de sua captação e a repercussão dessa informação provavelmente são diferentes.

\section{O PROFESSOR, O LOCAL E O MUNDIAL}

$\mathrm{O}$ educador, sabendo dessa diversidade, não pode deixar de considerar a especificidade do aluno. O professor é um agente de cultura tanto quanto os programas da TV e do computador.

A decisão em assistir ou não ao programa oferecido é do domínio da família. O Estado interfere na censura (recomendando para uma determinada faixa etária) mas não na produção (a não ser na TV oficial do Estado, como a TV Cultura). A TV trabalha temas como meio ambiente, saúde, violência apenas no nível do senso comum. Por outro lado, tais temas não compõem as disciplinas na escola. Como conseqüência, há invasão da escola e vulgarização da TV.

Os novos produtos advindos do desenvolvimento tecnológico são muito mais do que apenas produtos. Eles se constituem em novos conceitos. São freqüentemente ferramentas de trabalho até indispensáveis e se tornam, cada vez mais, portadores de uma nova maneira de pensar, trabalhar, pesquisar e educar. Já fazem parte da vida das pessoas e de instituições. A tendência é entrarem, cada vez mais, nas atividades cotidianas dos centros de pesquisa, das universidades, das indústrias, exigindo, inclusive, o estabelecimento de rede de computadores que permita a comunicação entre os equipamentos e entre as pessoas localizadas em diferentes partes do mundo. Pais e educadores acreditam que eles irão revolucionar a sala de aula e modificar as oportunidades das crianças quanto a uma vida melhor.

É inexorável a entrada dessa tecnologia de informação/comunicação também na escola que, como toda a instituição, é caracterizada como mantenedora de valores, de hierarquias, reprodutora de conhecimentos. Já são muitas as escolas que têm computadores, mas freqüentemente para uso administrativo ou como facilitador na redação de textos (quase só substituto da máquina de escrever).

O salto qualitativo na sala de aula, com a introdução de programas de computador que avancem na aprendizagem do aluno, depende do acesso dos professores aos avanços técnicos/científicos. Não apenas universalizar o acesso mas conquistar a universalização do conhecimento e da informação.

A escola será melhor se tiver computadores para o uso dos alunos, com a condição de que tenha bons professores, de preferência portadores de conhecimentos sobre o uso dessas novas ferramentas.

O computador é criação tecnológica independente e tem sido empregado como instrumento de ensino desde as primeiras séries da educação fundamental. Teve seus precursores, como as máquinas de ensinar, 
pensadas e criadas por educadores na década de 60. Quando se iniciou o debate referente às máquinas de ensinar não se afirmava que ela iria substituir o professor. $\mathrm{O}$ argumento mais forte é que ela iria libertar o docente de tarefas repetitivas, permitindo colaborar mais com a formação do aluno e torná-lo parceiro de sua aprendizagem.

\section{O PAPEL DO PROFESSOR}

Nos tempos pós-modernos de hoje, é anunciada por Lyotard a morte do professor $^{2}$, não só como resultado da presença física do computador mas em decorrência de uma falência pedagógica e epistemológica. Às máquinas pode-se pedir que substituam o trabalho humano não o intelecto humano. Cabe ao professor permanecer como agente de formação, indispensável na experiência educativa do aluno e não apenas como o transmissor de informações e habilidades necessárias a essas aquisições.

$\mathrm{O}$ professor é alguém que interage com o aluno de forma a facilitar suas experiências educativas e a instigar sua imaginação. O computador, apesar dos seus inúmeros recursos, tem limites precisos e irreversíveis. Abrem-se assim novas perspectivas para o trabalho do professor, desde que se disponha a trabalhar com os alunos em um plano criativo e inventivo.

É essa a questão que queremos levantar: os avanços tecnológicos não estão acoplados aos programas de formação de professor, pelo menos no Brasil. É preciso saber até que ponto ter acesso ao computador, integrar uma rede provoca mudanças nos programas dos cursos na Universidade, que são os centros lógicos de produção de conhecimento e de formação de profissionais.

É imprescindível refletir sobre essa questão, pois hoje os avanços tecnológicos pressionam as pessoas, indústrias, hospitais, enfim todos os locais de trabalho. A tecnologia exige uma preparação. A escola, e nela a formação de professores, está muito atrasada. A maioria dos lares tem TV, quase independentemente da renda salarial da família. As crianças que freqüentam as salas de aula são cadeira cativa de programas nos quais informações e conhecimentos são veiculados. Muitas escolas têm aparelho de TV e vídeo. Mas o professor raramente interage com eles, pode até levar o aparelho para as aulas, mas continuam a se apoiar rigidamente no livro didático ${ }^{3}$.

Fala-se hoje, em projetos governamentais, de dotar cada escola com antena parabólica, de "fazer o ensino via TV". A antena parabólica será um recurso educacional se os conteúdos, as mensagens estiverem inseridas no projeto pedagógico da escola. Sem essa inserção ela se torna um objetivo em si mesmo, portanto, vazia de significado para a aprendizagem. É o que nos alerta, por exemplo, Apple 4 , quando comenta a repercussão do Programa Um, obrigatório e diário em algumas escolas nos Estados Unidos e do qual os anúncios comerciais são os mais discutidos entre alunos e professores. Pode formar consumidores, e deve ser um dos objetivos, mas dificilmente alunos críticos e criativos.

A idéia corrente no senso comum é de que quanto maior a tecnologia, maior o conhecimento transmitido, o que é desmonta-

2. NUYEN.A.T. Lyotard, the death of the Professor. Educational Theory. Winter, v.42, n. 1, 1992. p.25-37.

3. Sobre o assunto ver: CITELLI, Adílson Odair. A circulação do texto na escola: mediações dos veículos de massa. Comunicação \& Educação. São Paulo: CCA-ECA-USP/Moderna, n.1, set./dez. 1994. p.21-26.

4. APPLE, Michel W. Is the new technology part of the solution or part of the problem in education? In: Teachers and Texts. New York/London: Routledge, 1989. p.150-174. 


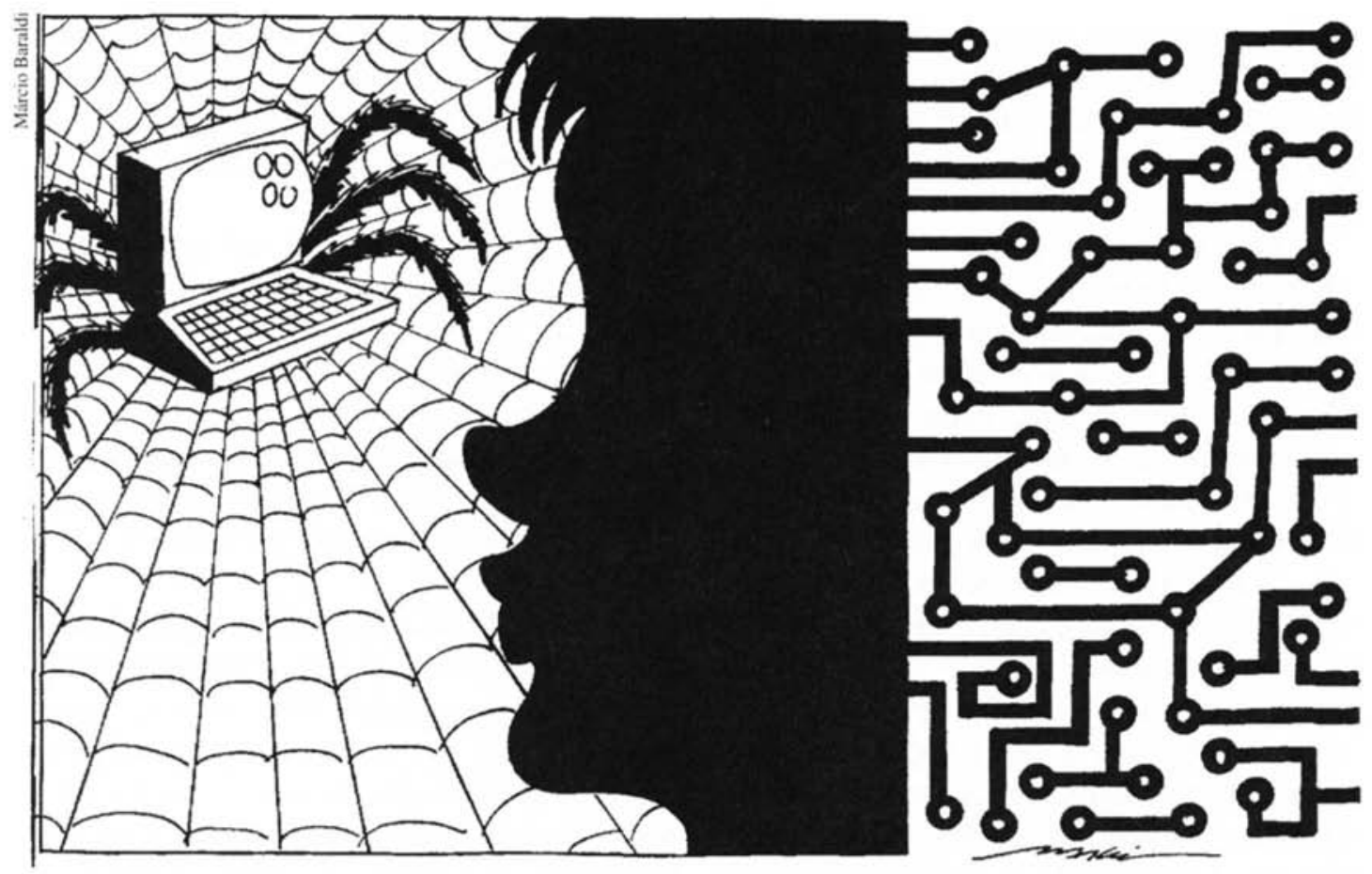

do por um raciocínio lógico mais atento. Um centro tecnológico na escola interessa não pela tecnologia mas pelo que se pode criar com ela.

A pouca literatura disponível, no momento, sobre o uso do computador no ensino aponta o professsor como elo indispensável entre o acervo tecnológico e a aprendizagem do aluno. Mas não está bem explicitada como fica modificada a função do professor quando a sala de aula é tomada por computadores. Há evidências de que as turmas de alunos melhor sucedidas em programas-pilotos são aquelas nas quais o instrutor está mais presente e não aquelas em que há um computador para cada alunos.

A elaboração dos programas, a seleção dos hipertextos, a consulta a fontes bibliográficas selecionadas exige a competência de professores. Uma das características dos artefatos da tecnologia atual é o rompimento da continuidade, a possibilidade de quebrar a totalidade, porém mantendo uma multidisciplinaridade visual. Permanece a exigência de recompor o todo, de refazer ligações, orientadas pelo professor, impedindo fragmentações estéreis ou acumulação desordenada de informações.

Há inevitavelmente um desarranjo provocado pelo novo paradigma tecnológico que é a informatização. No entanto, não dá para pensar que apenas incorporar os novos recursos da comunicação/informação seja a garantia para uma nova escola, nova educação, novos alunos. Há o perigo de apenas formar usuários sem se chegar a modificar essencialmente a aprendizagem, pois processar informações não implica necessariamente pensar, refletir, produzir conhecimento, que é um dos objetivos da escola, 
qualquer que seja sua seriação (educação básica, média ou universitária). Exige-se redimensionar a escola, alterar sua organização, modificar os espaços, regular o tempo de outra forma.

O novo desafio provoca, na realidade, um impasse. O professor torna-se aluno dos desafios, vira professor-parceiro de alunos que também estão enfrentando desafios provocados. A sala de aula pode tornar-se um ambiente interativo de aprendizagem. Há um acervo grande de informações e qual é o professor que tem condições de incorporá-lo?

A formação/cursos de preparação para o Magistério (Habilitação Específica para o Magistério de primeiro grau - HEM; Centro Educacional de Formação e Aperfeiçoamento do Magistério - CEFAM) e Licenciaturas ainda não definiram programas que incorporem o aprendizado sob as novas condições de tecnologia. E os equipamentos, em si, não respondem pela qualidade do ensino na escola.

Suprindo a escola de tecnologia, o que faltaria para atender o aluno na sua aprendizagem: ensino do que já está reconhecido como verdade, ganhar tempo (visão global em menos tempo), dar novo formato aos as-

Resumo: As autoras discutem a permanente importância do professor bem preparado para que se possa usar adequadamente a informática na escola. Afirmam que essas novas tecnologias já estão presentes nas vidas de professores e alunos e que, cada vez mais, são portadoras de conceitos e de uma nova maneira de pensar.

Palavras-chave: informática, professor, escola, comunicação, tecnologia suntos antigos, trabalhar temas inovadores. Mesmo que o professor não tenha formação ativa o computador deve ser usado, pois é conquista irreversível, é comunicação de alto valor.

O uso da tecnologia, da informática não é neutro. Como tecnologia, ela tem o poder de transformar nossa experiência. Amplifica e reduz aspectos dos temas que são propostos para estudo. Porém há predominância do como, sobre o que acontece e por quê, o que exige questionar sua neutralidade e indagar da potencialidade de seus efeitos secundários.

Hoje não se coloca mais a questão do conhecimento técnico para o uso eficiente e correto do computador. Mas deve-se indagar como esta ferramenta se ajusta ao processo de socialização do aluno e qual o preparo, no caso do professor, para que consiga minimizar e superar possíveis distorções com relação aos objetivos sociais e individuais da escolarização. Além de proporcionar/facilitar o uso em tarefas instrucionais, cabe à escola predizer e avaliar como se realiza essa aprendizagem, quais as referências fixadas no pensar e sentir dos novos alunos com as novas máquinas.

Abstract: The authors discuss the permanent importance of adequately prepared teachers in the order to use the computer as a pedagogical resource in school. They state that these new technologies are already part of the lives of students and teachers, and that they are more and more responsible for conveying concepts and new ways of thinking.

Key-words: computer science, teacher, school, communication, technology 